\title{
EVOLUTION ANALYSIS OF WATERCOURSE AND SHOALS OF THE XUNJIANG RIVER IN WUZHOU BASED ON TIME-SERIES REMOTE SENSING DATA
}

\author{
Yongliang Du ${ }^{1,2}$, Guiwen Lan ${ }^{1,2, *}$, Yaping Hua ${ }^{1,2}$, Jianjun Chen ${ }^{1,2}$, Donglin Fan ${ }^{1,2}$, Zhuguang Pan ${ }^{1,2}$ \\ ${ }^{1}$ Guangxi Key Laboratory of Spatial Information and Geomatics, Guilin University of Technology, Guilin, China - (291296038, \\ 23955461, 2272133181, 454818136, 812060461, 2277647553)@qq.com \\ ${ }^{2}$ College of Geomatics and Geoinformation, Guilin University of Technology, Guilin, China
}

KEY WORDS: Watercourse and Shoals, Time-series Remote Sensing Data, Wuzhou Reach of Xunjiang River, Evolution Analysis

\begin{abstract}
:
Wuzhou reach of Xunjiang River is the most valuable waterway in Guangxi. The research on the evolution of Xunjiang River in Wuzhou is of great practical significance in the aspects of river regulation and water conservancy construction. Based on Landsat images of normal water level in 1997, 2001, 2005, 2009, 2014 and 2018, this paper firstly conducts a quantitative analysis of evolution of the watercourse and shoals in Wuzhou section of Xunjiang River through using RS and GIS. Then the relationships between the changes of river course and sandbars of the research area and the annual rainfall and vegetation coverage of the upstream region are analyzed to determine the causes of the changes of watercourse and shoals of Xunjiang River in Wuzhou. The results show that the riverway contracted with a contraction amount of about $9.93 \mathrm{~km}^{2}$ from 1997 to 2005 , and the expansion volume of sandbars was about $12.21 \mathrm{~km}^{2}$. From 2005 to 2014 , the watercourse approximately expanded $12.33 \mathrm{~km}^{2}$, and the shoals shrank about 12.49 $\mathrm{km}^{2}$. From 2014 to 2018 , the river course was a contraction trend, reducing about $1.57 \mathrm{~km}^{2}$ in area; the sandbars showed an expanding trend, with an expanding amount of about $0.82 \mathrm{~km}^{2}$. The changes of river channel and shoals are mainly influenced by the incoming water and silt from the upper reaches and are related to the annual rainfall and vegetation coverage of the upstream area. The correlation coefficient between watercourse area and upstream annual rainfall is 0.26 , and that between riverway area and upstream vegetation coverage is 0.78 . However, the correlations between the area of shoals and the annual rainfall and vegetation coverage of the upstream region are contrary to that of the river channel. The correlation coefficients between the area of shoals and the annual rainfall and vegetation coverage of the upstream district are -0.28 and -0.83 respectively.
\end{abstract}

\section{INTRODUCTION}

As time changes, river courses usually change due to natural factors and human activities (Mao et al., 2009). Watercourse changes have an important impact on the ecological environment, economic construction and waterway regulation of the river basin. The evolution of shoal reflects the changes of inflow and sediment from the upstream and the surrounding environment of the channel, which is the research focus of hydrology and water conservancy. Some scholars have studied the evolution of river channels and shoals. For example, Sun et al. (2011) analyzed the evolution of channel and shoals of the middle Yangtze River from Chenglingji to Hukou by using channel observation data, and dissected the causes of navigation obstruction and proposed governance strategies. Xue et al. (2018) used three ETM+ images before and after the impoundment of the Three Gorges Reservoir to analyze the change of scour and silting and morphological evolution of shoals in Jingjiang reach of the middle Yangtze River, and found the differences in the scour and silting dynamics, distribution and morphological evolution of the upper and lower Jingjiang River. Zhao et al. (2016) used TM remote sensing images combined with RTK data to analyze the tendency of river oscillation and the change of channel width in the reach of Yellow River from Pugebo to Chahekou, and concluded that the river morphology interpreted by remote sensing images is in good agreement with the measured river morphology. However, most of the current literature that study the changes of river channels and shoals are about the Yangtze River and the Yellow River, and there are relatively few reports

* Corresponding author on the evolution of watercourses and shoals in other rivers such as the Xunjiang River and Xiangjiang River by using Remote Sensing (RS) and Geographic Information System (GIS) technology, which has restricted the local river improvement, the economic development of the basins and the rational development and utilization of the sandbars and shoals.

In addition, it is difficult to carry out a macroscopic and comprehensive research on river channels and shoals by using conventional monitoring methods, while RS has the advantages of rapid, macroscopic and intertemporal, and can be used for large-scale investigation and monitoring for a long time, which plays a special role in studying the changes of watercourses and shoals (Zhong et al., 2006). As a powerful tool for geospatial data processing, analysis and mapping, GIS can provide reliable analyses of the changes of river channels and shoals (Yin et al., 2011). Therefore, based on time-series remote sensing data, this paper uses GIS technology to analyze the evolution characteristics of the river course and shoals of Wuzhou reach of Xunjiang River, and to explore the causes of their changes.

\section{RESEARCH AREA AND DATA SOURCES}

\subsection{Study Area}

Xunjiang River is the middle reach of Xijiang River in the Pearl River basin, which is located in the lower reach of Qianjiang River and the upper reach of Xijiang River. The research area of this paper is the Wuzhou reach of Xunjiang River (as shown in Figure 1), which is located between $110^{\circ} 35^{\prime}$ E- $111^{\circ} 25^{\prime} \mathrm{E}$ and $23^{\circ} 26^{\prime} \mathrm{N}-23^{\circ} 28^{\prime} \mathrm{N}$, with a length of about 98 $\mathrm{km}$ and an catchment area of $20,236 \mathrm{~km}^{2}$. The water surface is wide, varying from 340 to 2600 meters, with an average of 750 
meters. The water depth of the watercourse is between 3 and 50 meters, with many shoals, sandbars and branching channels. There are sufficient water and abundant water energy in this reach. The reach that is open to the four seasons is the most valuable waterway in Guangxi. The study on the evolution of the river channel and shoals can provide scientific basis for the economic construction, river regulation and water conservancy construction of the river basin, and has certain practical significance.

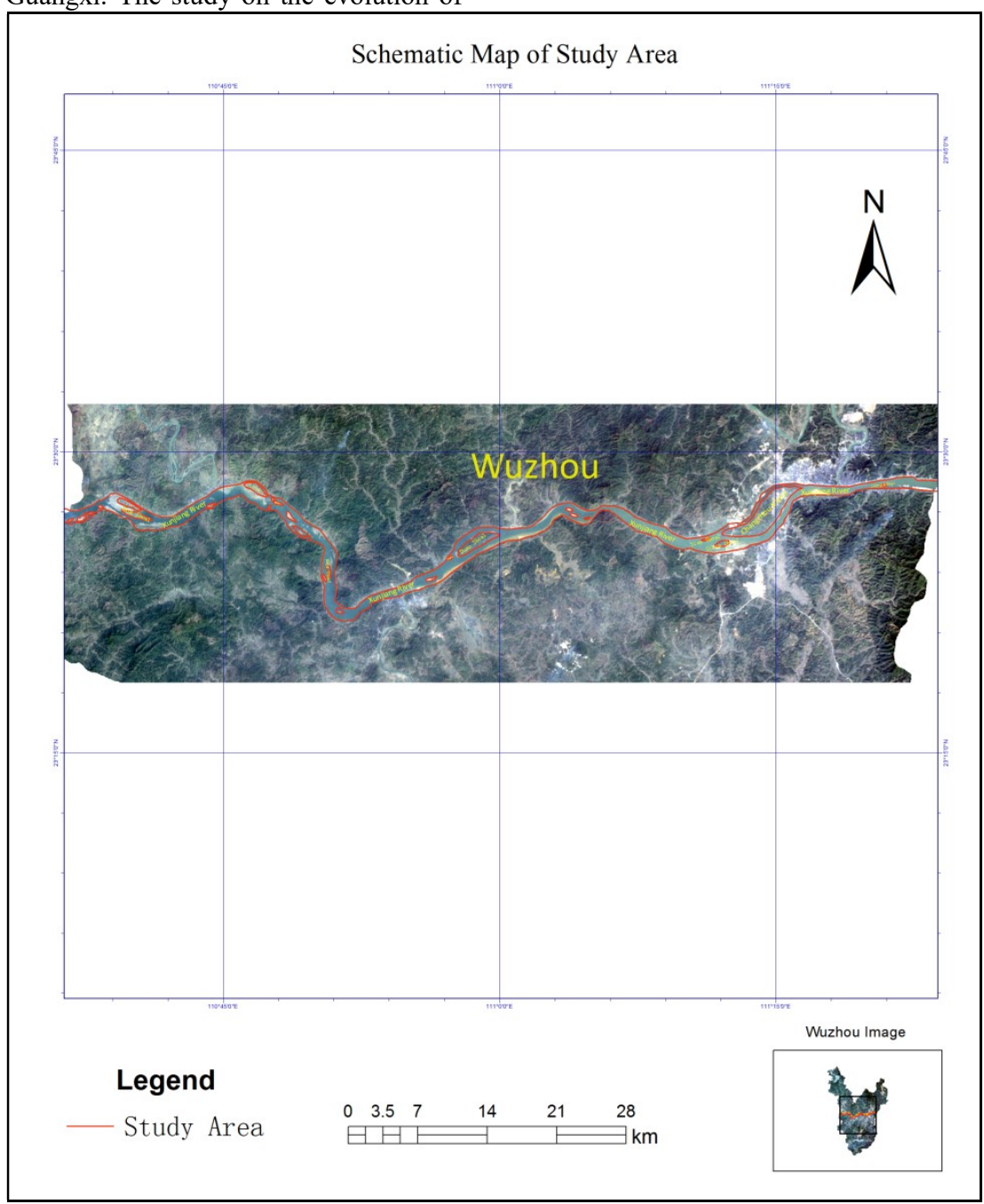

Figure 1. Map of study area

\subsection{Data Sources}

In order to obtain river information on a large scale and quickly analyze the change characteristics of river channels and shoals as a whole, it is no doubt that satellite image has become the preferred research data. Landsat is a land satellite of the United States. It not only has a long time series and a large spectral range, but also contains bands with low reflectivity to water. It is easy to distinguish land and water boundaries, and can extract water and non-water information in a good and convenient way. Furthermore, considering the accessibility of remote sensing data, spatial resolution, temporal resolution, cost-benefit ratio and other factors, this paper chooses Landsat5 and Landsat8 images in 1997, 2001, 2005, 2009, 2014 and 2018 (as shown in Table 1) to carry out the evolution study of river channel and shoals in the research area for nearly 20 years. In order to avoid the influence of low-water period and high-water period, the selected image data are in normal-water period, and their cloud cover is less than $8 \%$. The image data of research area can well reflect the ground feature information. At the same time, the remote sensing data is supplemented by other data.

\begin{tabular}{|c|c|c|c|c|c|}
\hline Satellite / Sensor & Path & Row & Date of imaging & Spatial resolution(m) & source \\
\hline Landsat5/TM & 124 & 44 & $1997-10-30$ & 30 & $\mathrm{http}: / /$ www.gscloud.cn \\
\hline Landsat5/TM & 124 & 44 & $2001-11-26$ & 30 & $\mathrm{http}: / /$ www.gscloud.cn \\
\hline Landsat5/TM & 124 & 44 & $2005-11-21$ & 30 & $\mathrm{http}: / /$ www.gscloud.cn \\
\hline Landsat5/TM & 124 & 44 & $2009-10-31$ & 30 & $\mathrm{http}: / /$ www.gscloud.cn \\
\hline Landsat8/OLI & 124 & 44 & $2014-11-14$ & 30 & $\mathrm{http}: / /$ www.gscloud.cn \\
\hline Landsat8/OLI & 124 & 44 & $2018-11-25$ & 30 & $\mathrm{https://earthexplorer.usgs.gov}$ \\
\hline
\end{tabular}

Table 1. Remote sensing data sources 


\section{DATA PROCESSING AND INFORMATION EXTRACTION}

\subsection{Images Processing}

The downloaded Landsat images belong to Level $1 \mathrm{~T}$ digital products, which have been carried out systematic radiometric correction and geometric correction of ground control points, as well as terrain correction through Digital Elevation Model (DEM). The accuracy of these products has basically met the needs of this paper. The downloaded Landsat images are TIFF images, and the bands are stored separately. So in order to facilitate subsequent processing and operation, the bands of each image are combined by ENVI software, and then the images after the combination of bands are cropped by the cropping tool of ENVI to obtain the images of the study area.

Image enhancement can improve the visual interpretation performance of remote sensing images and enhance the target information, which is conducive to the subsequent processing and analysis of remote sensing images (Wu, 2017).The methods of remote sensing image enhancement mainly include contrast enhancement, spatial filtering, color conversion, image operation and spectral enhancement and so on (Reddy, 2018). In order to enhance the boundary between water and land, this paper mainly uses image operation to process the cropped images.

\subsection{Information Extraction of Watercourse and Shoals}

There are many methods for water information extraction based on remote sensing images, which can be roughly divided into water information extraction method based on band operation, mixed pixel decomposition method, decision tree classification method and traditional classification method, etc. (Zhang, 2016). Each method has its own applicability. For channel information extraction, most of the methods are based on band operation, which can be divided into single-band method and multi-band method. The single-band method mainly extracts water information based on the characteristics that the reflectivity of water decreases with the increase of wavelength and has the lowest reflectivity in the near-infrared band $(\mathrm{Li}$, 2018). But the single-band method is difficult to set appropriate threshold value to extract water information accurately. Multi-band method mainly operates on multiple bands, aiming at highlighting the Water information and inhibiting the non-water information. The most commonly used methods are the spectrum-photometric method and the modified normalized difference water index (MNDWI).

MNDWI was put forward by $\mathrm{Xu}$ (2005) based on the improvement of the normalized water index method (NDWI), and its calculation formula is:

$$
\text { MNDWI }=\frac{\text { Green I MIR }}{\text { Green + MIR }}
$$

Where $\quad$ Green $=$ green band of image MIR $=$ mid-infrared band of image

MNDWI can effectively solve the problem of not being able to extract water body information in places with many buildings, and the effect on shadow is also effectively eliminated.
The spectrum-photometric method was proposed by $\mathrm{Du}$ and Zhou (1998) to build a water information extraction model based on TM image by combining appropriate bands. The calculation formula is:

\section{$\mathrm{TM} 2+\mathrm{TM} 3>T M 4+T M 5$}

(2)

Where

$$
\begin{aligned}
\text { TM2 } & =\text { green band of TM image } \\
\text { TM3 } & =\text { red band of TM image } \\
\text { TM4 } & =\text { near-infrared band of TM image } \\
\text { TM5 } & =\text { mid-infrared band of TM image }
\end{aligned}
$$

The spectrum-photometric method is also applicable to Landsat8 OLI images, but the operational bands correspond to the 3, 4, 5 and 6 bands of Landsat8 OLI image respectively. The spectrum-photometric method also has the advantage of distinguishing water from shadow.

The MNDWI method and spectrum-photometric method have the advantages of separating water from shadow and improving the precision of water extraction. They also binarize the image (the water pixel value is 1 , and the non-water pixel value is 0 ) through band operation. Only by setting the pixel threshold value, water information can be extracted. In this paper, the relevant tests are carried out on these two methods, and it is found that both of them can extract main stream channel information well, but as shown in Figure 2, the MNDWI method extracts more small water bodies than the spectrum-photometric method, and these small water bodies need to be processed so as to retain only main stream channel information. Therefore, spectrum-photometric method is used to extract watercourse information in this paper. The specific methods are as follows:

Band Math function of ENVI is used to binarize the images of the study area through the spectrum-photometric method.

Raster to Vector function of ENVI is used to extract water body information and non-water body information (including shoals information) by setting pixel threshold values as 1 and 0 respectively.

The vector data of water and non-water are output in ENVI as the Shapefile data supported by ArcGIS.

(4) The Shapefile data are processed in ArcGIS to extract water body and non-water body boundaries, edit their attributes and perform spatial analysis and statistical analysis, etc.

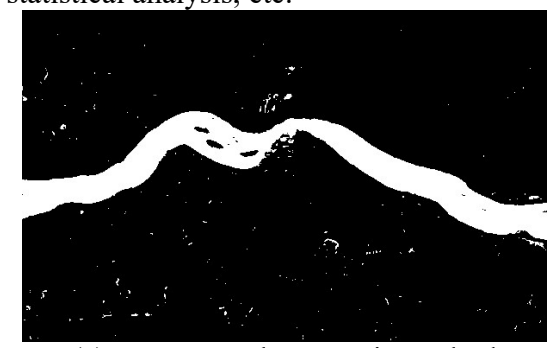

(a) Spectrum-photometric method 


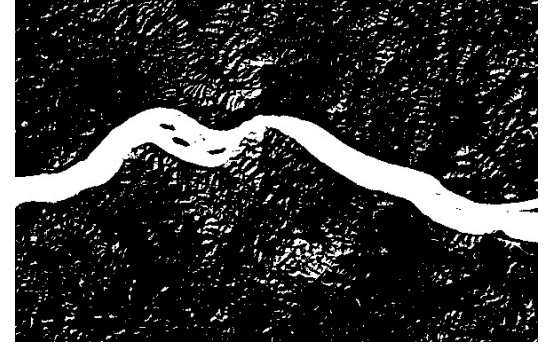

(b) MNDWI

Figure 2. Comparison figure of water extraction effect of two methods

\section{ANALYSIS OF WATERCOURSE AND SHOALS VARIATION}

\subsection{Qualitative analysis of watercourse and shoals}

Through the above-mentioned operation method, each temporal river channel and shoals boundaries are extracted, and they are superimposed to analyze the changes of watercourses and shoals between each time period. As shown in Figure 3, compared with 1997, the river channel showed a great shrinking trend in 2001. The watercourse in 2005 contracted more generally than in 2001, with some river channels contracting more, while others contracting less or not. In 2009, compared with 2005 , there was a large expansion of river course. In 2014, the river channel was expanded compared with that in 2009, but the trend was not big. The river channel in 2018 showed a smaller shrinkage trend than in 2014. For the evolution of the shoals, there is an opposite situation with the evolution of the channel. From 1997 to 2005, shoals were expanding, the upstream end of which was larger and the downstream end was smaller. The expansion was larger in 2001 than in 1997 but smaller in 2005 than in 2001. From 2009 to 2014, the shoals showed a trend of contraction. Especially in 2009 , compared with 2005 , the shoals contraction trend was quite large, but in 2014, the shoals contraction trend was relatively small. In 2018, compared with 2014, shoals showed an expansion trend, but not a big one.

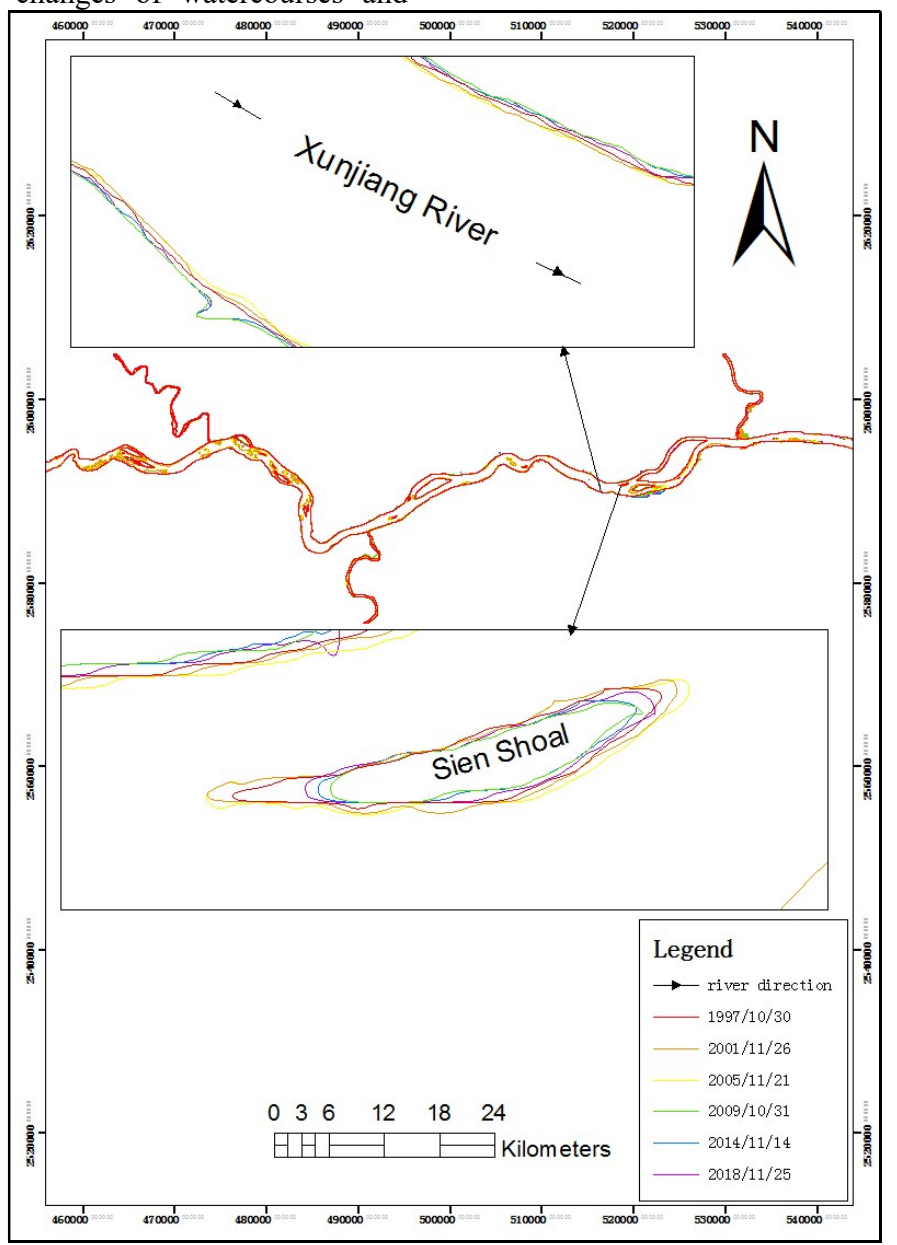

Figure 3. Map of channel and shoal boundary at different time periods

\subsection{Quantitative analysis of watercourse and shoals}

In the research area, the river channel is long and there are many sandbars and shoals. Not every place is in the state of expansion or contraction. For example, some places are in the state of expansion, and some places are in the state of contraction, and even others are unchanged. Therefore, it is necessary to calculate the expansive volume and shrinkage of river channel and shoals respectively, and determine which is dominant by comparing their sizes. For example, if the expansive volume of a channel is greater than its shrinkage, the channel tends to expand.

In order to calculate the amount of expansion of the watercourse, this paper overlap the former temporal layer (excluding the shoal) of the non-water with the latter temporal layer of the main stream water in ArcGIS, and calculate the area of the intersection layer. But the calculation of the contraction of the river channel is reversed. For the calculation of shoals expansion amount, this paper adopts the method of 
overlapping the main stream water layer of the former time with the shoals layer of the latter time and calculating the intersection layer area. However, the shrinkage of the shoals is calculated by using the opposite layers.

The amount of expansion and contraction of watercourse and shoals between each time are calculated through the above-mentioned method, and the corresponding column diagram is drawn. As shown in figure 4 (a), from 1997 to 2005, the riverway contraction amount in the study area is larger than the expansion amount, and the shrinkage of watercourse was $6.05 \mathrm{~km}^{2}$ from 1997 to 2001 and $3.88 \mathrm{~km}^{2}$ from 2001 to 2005 . The riverway expansion volume was the largest from 2005 to 2009, reaching $10.15 \mathrm{~km}^{2}$. However, from 2009 to 2014, the river expansion volume decreased to $2.18 \mathrm{~km}^{2}$. From 2014 to 2018 , the expansion volume of river channel is less than the contraction volume, and the shrinkage is $1.57 \mathrm{~km}^{2}$. As shown in figure 4 (b), the amount of expansion and contraction of shoals are opposite to that of watercourse. From 1997 to 2005, the expansion volume of shoals was larger than the shrinkage, and the amount of expansion was $7.71 \mathrm{~km}^{2}$ from 1997 to 2001 and $4.50 \mathrm{~km}^{2}$ from 2001-2005. From 2005 to 2014, the contraction volume of shoals was larger than the expansion volume. In particular, from 2005 to 2009 , the contraction of the shoals was the largest, as high as $11.65 \mathrm{~km}^{2}$. However, the volume is less from 2009 to 2014, only $0.82 \mathrm{~km} 2$. From 2014 to 2018, the amount of expansion of shoals is larger than the shrinkage, but its expansion volume is small, only $0.82 \mathrm{~km} 2$.

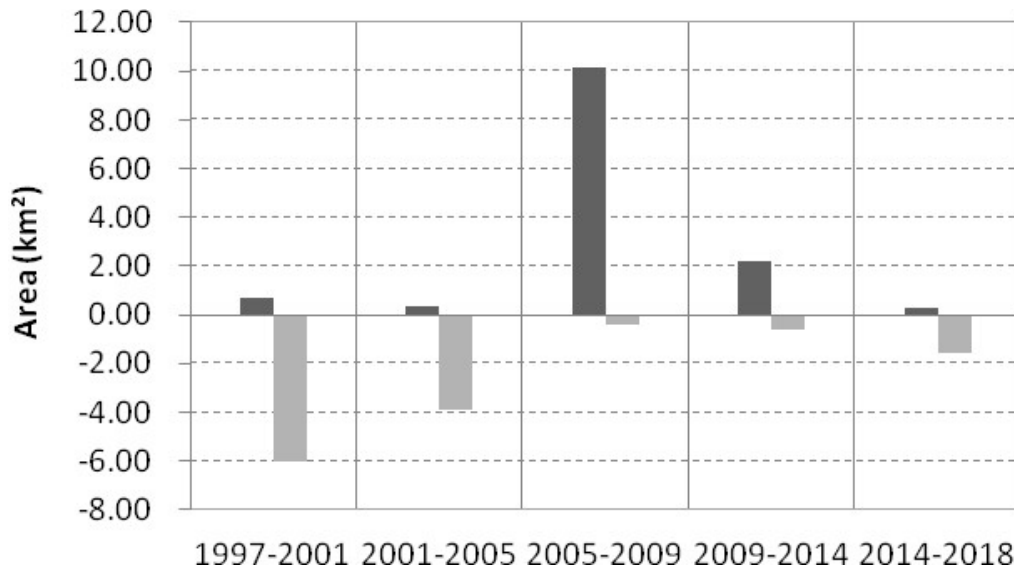

Expansion amount

- Shrinkage amount

(a) Histogram of channel expansion and contraction

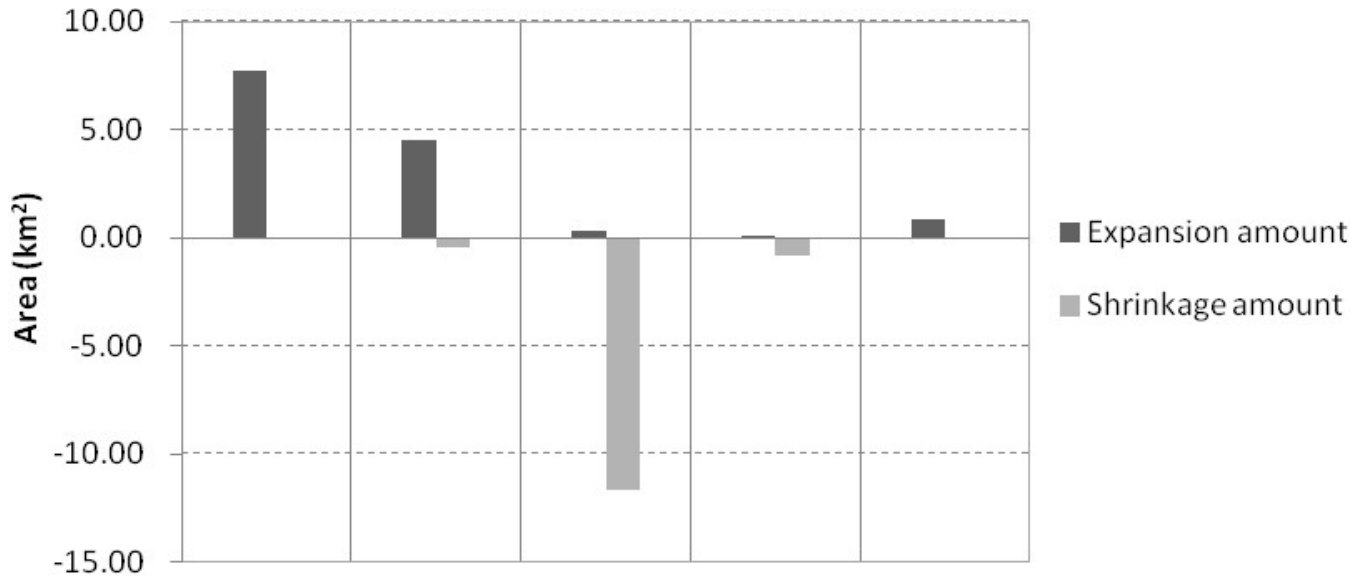

1997-2001 2001-2005 2005-2009 2009-2014 2014-2018

(b) Histogram of shoals expansion and contraction

Figure 4. Comparison chart of expansion and contraction of river channel and shoals in the study area

\subsection{Cause analysis of watercourse and shoals variation}

The changes of watercourse and shoals are effected by the upstream water and sand, which is correlated with the rainfall and vegetation coverage of the upstream area. When the rainfall and vegetation coverage of the upstream region become less, the water is less and the sand is more in upper reaches, resulting in siltation of the shoals and narrowing of the river channel. On the contrary, when the upstream rainfall and vegetation coverage increase, there will be more water and less sand in the upstream, which will lead to the scour of the shoals and widening of the watercourse. Based on the annual rainfall data (from statistical yearbook of Guangxi) and vegetation coverage data (obtain by images computing) of the upstream region, this paper explore the correlations between them and the changes of watercourse and shoals of the study area. It is found that the watercourse area of the study area is positively correlated with the annual rainfall and vegetation coverage of the upstream region. The correlation coefficient between riverway area and annual rainfall is 0.26 , and the correlation coefficient between river channel area and vegetation coverage is 0.78 . However, the correlations between the shoals area and the upstream annual rainfall and vegetation coverage are contrary to that of the watercourse. The correlation coefficient between the shoals area and the upstream annual rainfall and the correlation coefficient between the shoals area and the upstream vegetation coverage are -0.28 and -0.83 respectively. 
In addition, the changes of watercourse and shoals are also affected by human factors, such as the construction of dams, reservoirs, bridges and so on. It is needed to intercept the river so that the river level drops sharply, and the area of the river channel and shoals varies greatly. During the period from 1997 to 2009, the area of watercourse and shoals in Wuzhou reach of Xunjiang River had changed greatly. Especially from 2005 to 2009 , the area of the river course and shoals changed abruptly. According to the investigation data, it was mainly due to the construction of Changzhou water conservancy project in Wuzhou during this period. The river was blocked, and the river water level dropped. The channel area rapidly contracted, and the area of shoals increased sharply. After the completion of the construction of the Changzhou water conservancy project, the river water level rose rapidly, resulting in a great increase of the watercourse area and a sharp decrease of the shoals area.

\section{CONCLUSIONS}

This paper studies the evolution of watercourse and shoals of Xunjiang River in Wuzhou by using Landsat images of six time-periods from 1997 to 2018 and draws the following conclusions:

(1) Between 1997 and 2009, the areas of river channel and shoals of Wuzhou reach of Xunjiang River changed a lot, which are mainly affected by human activities.

(2) The changes of watercourse and shoals are influenced by the upstream inflow and sediment, and they are correlated with the rainfall and vegetation coverage of the upstream area. The area of river channel is positively correlated with rainfall and vegetation coverage of the upstream region. However, the correlations between shoals area and the upstream rainfall and vegetation coverage are opposite to that of watercourse.

(3) Using GIS to study the evolution of river channels and shoals based on remote sensing images can expediently realize the changes of river channel and shoals, and has the advantages of macro, rapid and intuitive, etc. The analysis method combining remote sensing and GIS technology is an effective method to quickly analyze the changes of watercourses and shoals.

\section{ACKNOWLEDGEMENTS}

The research work is supported by National Natural Science Foundation of China under Grant No.41861050.

\section{REFERENCES}

Du, Y.Y., Zhou, C.H., 1998. Automatically extracting remote sensing information for water bodies. Journal of Remote Sensing, (4), 264-269.

Li, L.L., 2018. The RS module of water information extraction (MWE) designing and implementing based on IDL/ENVI. Liaoning Normal University, Dalian, Liaoning province, China.

Mao, F., Huang, J.X., Hu, Q., Zhou, W.S., Li, Q., Liu, Z., 2009. Analysis of evolution of rivers and driving force in the Qingkou region based on multi-source remote sensing data. Journal of Tsinghua University (Science and Technology), 49(3), 313-316.
Reddy, G.P.O., 2018: Digital Image Processing: Principles and Applications. Springer Nature, Cham.

Sun, Z.H., Li, Y.T., Huang, Y., Gao, K.C., 2011. Fluvial process of sandbars and shoals in branching channels of the middle Yangtze River. Journal of Hydraulic Engineering, 42(12), 1398-1406.

Wu, S.H., 2017. Research on preprocessing and analysis methods for remote sensing images. Nanjing University of Aeronautics and Astronautics, Nanjing, Jiangsu province, China.

Xue, X.H., Chang, S., Song, E.P., 2018. Evolution of floodplains and bars at the Jingjiang reach of Yangtze River, China in response to Three Gorges Reservoir impoundment. Acta Geographica Sinica, 73(9), 1714-1727.

Xu, H.Q., 2005. A study on information extraction of water body with the modified normalized difference water index (MNDWI). Journal of Remote Sensing, (5), 589-595.

Yin, P.L., Dai, S.B., Yu, X.X., 2011. Remote sensing analysis of evolution of the Yangtze River in Anhui province based on GIS. Surveying and Mapping, 34(1), 28-33.

Zhao, S.X., Li, C.Y., Li, C., Shi, X.H., Sun, B., Zhao, S.N., 2016. Analysis of characteristics of river channel evolution in Inner Mongolia reach of Yellow River based on 3S technology. Advances in Science and Technology of Water Resources, 36(4) 70-74.

Zhong, K.W., Liu, W.X., Huang, J.M., 2006. A riverway evolution analysis based on remote sensing technique: A case study of the lower reaches of the Beijiang River. Remote Sensing for Land \& Resources, (3), 69-73.

Zhang, Y.C., 2016. Research on the method of water body extraction based on remote sensing image-The case of Qinghai Lake. Northwest University, Xian, Shaanxi province, China. 